\title{
Influences of Variation in Total Energy Intake and Dietary Composition on Regulation of Fat Cell Lipolysis in Ideal-Weight Subjects
}

\author{
H. Kather, E. Wieland, A. Scheurer, G. Vogel, U. Wildenberg, and C. Joost \\ Klinisches Institut für Herzinfarktforschung an der Medizinischen Universitätsklinik Heidelberg, D-6900 Heidelberg, \\ Federal Republic of Germany
}

\begin{abstract}
Weight-maintaining fat-rich, "prudent," carbohydrate-rich, as well as energy-restricted diets $(300 \mathrm{kcal} / \mathrm{d})$ were fed in succession for $7 \mathrm{~d}$ to 12 healthy males of ideal body weight under metabolic ward conditions. At the end of each period isolated fat cells were prepared from subcutaneous abdominal adipose tissue and incubated in vitro in the absence or presence of adenosine deaminase, either alone or in combination with various lipolytic or antilipolytic hormones and agents.

Variations in total energy intake and dietary composition had characteristic and specific effects on fat cell lipolysis in vitro. High carbohydrate and prudent diets resulted in low rates of nonstimulated glycerol release and impaired insulin action in the presence of adenosine deaminase $(320 \mathrm{mU} / \mathrm{ml})$. High-fat and energy restricted diets were characterized by high rates of nonstimulated glycerol release. Sensitivity of antilipolysis to insulin and prostaglandin $E_{2}$ was 10 to 200 times lower respectively on energy-restricted than on fat-rich diets. The effects of $\alpha_{2}$ - and $\boldsymbol{\beta}$-adrenergic catecholamines and of $\mathbf{N}^{6}$-phenylisopropyladenosine were not affected by the preceding diets.
\end{abstract}

\section{Introduction}

Variations in total energy intake and composition of daily food play an important role in the regulation of metabolic processes both in animals and man (1). Recognizing the prominent role of adipose tissue in the formation, storage and supply of energy reserves, considerable attention has been paid to metabolism of this tissue (2-7).

In human adipose tissue lipolysis can be stimulated by $\beta$ adrenergic catecholamines and parathyroid hormone (8). Other agonists, e.g., adenosine, prostaglandins of the E-type, $\alpha_{2}$-adrenergic agonists and insulin, act through specific receptors to inhibit lipolysis $(1-3,8)$. The mechanism by which the antilipolytic effect of insulin is mediated is not understood (9). The other agents are thought to exert their effects by activation or inhibition of adenylate cyclase (1-3). According to current understanding receptors for the inhibitory agonists are coupled to adenylate cyclase by a guanine nucleotide binding protein $\left(\mathrm{N}_{\mathrm{i}}\right)$ distinct from that $\left(\mathrm{N}_{\mathrm{s}}\right)$, which couples receptors for stimulatory agonists to the enzyme (10).

The present knowledge about dietary effects on lipid mobilization in human beings is largely confined to fat tissue from

\footnotetext{
Address reprint requests to Dr. Kather.

Received for publication 1 August 1986 and in revised form 26 December 1986.
}

J. Clin. Invest.

(c) The American Society for Clinical Investigation, Inc.

0021-9738/87/08/0566/07 \$2.00

Volume 80, August 1987, 566-572 obese donors. Previous studies revealed that, in the obese, nonstimulated lipolysis is selectively increased by energy restriction while the transmission of stimulatory and inhibitory hormonal inputs was essentially unchanged $(11,12)$. Detailed information about nutritional influences on regulation of lipolysis in normal man is lacking at present. Therefore, the effects of four different diets, varying in total energy content and composition on fatcell lipolysis were compared under metabolic ward conditions in 12 healthy young males of ideal body weight.

\section{Methods}

Subjects. 12 healthy male students of ideal body weight were admitted to the metabolic ward of our institution. Their age range was $24.8 \pm 1.0$ yr. Height and body weight averaged $182 \pm 2.8 \mathrm{~cm}$ and $73.5 \pm 1.6 \mathrm{~kg}$, respectively. The nature, purpose, and possible risks of the study were explained to all the involved subjects before their consent to participate was obtained. The study was approved by the local Ethical Committee. The volunteers stayed at the ward overnight (between 8:00 p.m. and 8:00 a.m.) and received their meals at the hospital, but were allowed to continue their studies and to maintain their usual physical activity.

All except one were actively engaged in sports and were physically fit as evidenced by the fact that all were able to do bicycle exercise at at least $200 \mathrm{~W}$ for $20 \mathrm{~min}$. All the subjects had normal fasting serum levels of insulin and glucose and were free from laboratory evidence for hepatic, renal, cardiovascular, or metabolic disease.

Protocol. The volunteers were subjected to four consecutive dietary regimens each lasting $7 \mathrm{~d}$. The sequence of dietary regimens was identical in all subjects. The protocol was started with an isocaloric high-fat diet, which was followed by weight maintaining "prudent" and high-carbohydrate diets and $1 \mathrm{wk}$ of energy restriction $(300 \mathrm{kcal} / \mathrm{d})$. The composition of the diets is given in Table I.

Biopsies. Specimens of subcutaneous fat tissue $(\sim 200-300 \mathrm{mg})$ were removed between 9:00 and 10:00 hours after an overnight fast for 13$14 \mathrm{~h}$. Abdominal adipose tissue was obtained from around the navel by needle biopsies which were carried out after intracutaneous anesthesia with lidocaine using needles of $2 \mathrm{~mm}$ diameter and a 20-ml syringe containing $2 \mathrm{ml}$ of $0.9 \% \mathrm{NaCl}$. The first biopsy was taken from the upper right half of the abdomen $5 \mathrm{~cm}$ from the navel; the following samples were placed in the same distance from the umbilicus in the lower right half, the lower left half and the upper left half of the abdomen, respectively.

Fat cell isolation and incubations. Fat cells were isolated by the method of Rodbell (13) in Krebs-Henseleit bicarbonate buffer, pH 7.4, containing $40 \mathrm{~g} /$ liter human serum albumin, $5 \mathrm{mmol} / \mathrm{liter}$ glucose and $2 \mathrm{mg} / \mathrm{ml}$ of collagenase (type II, Sigma Chemical Co., St. Louis, MO). After incubation for $45 \mathrm{~min}$ at $37^{\circ} \mathrm{C}$ cells were freed from connective tissue by filtering through a nylon screen and being washed three times by flotation. The cells were resuspended at a final concentration of $10,000-20,000$ cells/ml in the same medium except that collagenase was omitted. The cell number was determined by counting all cells in appropriately diluted aliquots $(10 \mu \mathrm{l})$ of cell suspensions.

Aliquots of the cell suspensions ( $50 \mu \mathrm{l}, 500-1000$ cells) were incubated in stoppered plastic vials $(2 \mathrm{ml})$ under $\mathrm{O}_{2}+\mathrm{CO}_{2}(95+5)$ for $180 \mathrm{~min}$. Incubations were terminated by heating $\left(95^{\circ} \mathrm{C}, 5 \mathrm{~min}\right)$.

Determinations. Glycerol release was determined by a bioluminescent method with minor modifications (14). For determinations of serum 
Table I. Total Energy Intake, Dietary Composition, and Body Weight

\begin{tabular}{lcccc}
\hline & Fat-rich diet & “Prudent" diet & Carbohydrate-rich diet & Energy restricted diet \\
\hline Total energy $(k c a l / d)$ (range) & 2,820 & 2,805 & 2,850 & 300 \\
& $(2,765-3,160)$ & $(2,740-3,040)$ & $(2,790-3,090)$ & 36 \\
Protein (\% of energy) & 16 & 16 & 16 & 44 \\
Vegetable protein $(\%$ of protein) & 22 & 37 & 42 & \\
Fat $(\%$ of energy) & 58 & 31 & 5 & 20 \\
P/S ratio & 0.15 & 1.8 & 131 & \\
Cholesterol $(m g / d)$ & 780 & 131 & 80 & \\
Carbohydrate $(\%$ of energy) & 26 & 53 & 22 & $68.8 \pm 1.5$ \\
Fiber $(g / d)$ & 7 & 18 & $72.9 \pm 1.5$ & \\
Body weight $(k g \pm S E)$ & $72.7 \pm 1.5$ & $72.8 \pm 1.4$ & & \\
\end{tabular}

free fatty acids and glycerol $100 \mu \mathrm{l}$ serum were acidified with $10 \mu \mathrm{l}$ of 1 $\mathrm{M} \mathrm{HCl}$ and neutralized with $10 \mu \mathrm{l}$ of $1 \mathrm{M} \mathrm{KOH}$. The samples were then diluted 10-50 times and assayed bioluminometrically $(14,15)$. Serum triglycerides and total cholesterol were measured enzymatically (16).

Materials. Enzymes and coenzymes were obtained from Boehringer, Mannheim, West Germany. The enzymes were spun down in a desk centrifuge and resuspended in Krebs-Henseleit bicarbonate buffer, $\mathrm{pH}$ 7.4. Isoproterenol, clonidine and $\mathrm{N}^{6}$-phenylisopropyladenosine were gifts of ICI-Pharma, Planckstadt, West Germany and Boehringer, Ingelheim, West Germany, respectively. Bovine insulin and prostaglandin $E_{2}$ were from Serva AG, Heidelberg, West Germany. Epinephrine and norepinephrine tartrate were purchased from Merck AG, Darmstadt, West Germany and Roth AG, Karlsruhe, West Germany, respectively.

Calculation of $E D_{50}$ and statistics. $\mathrm{ED}_{50}$ was estimated by linear regression analysis of individual dose-response curves by computing log lipolytic rate versus the log hormone concentration. The $\mathrm{ED}_{50}$ was the half of the difference between base-line levels and the effect of maximal concentrations of regulators. Individual $\mathrm{ED}_{\mathbf{5 0}}$ 's were compared by Wilcoxon's test which was also employed for evaluation of differences in efficacy between the antilipolytic agents tested. Pooled data are means \pm SE of at least seven experiments carried out in duplicate in the same subject on all four diets.

\section{Results}

Diet-induced changes in serum concentrations of lipids, free fatty acids, and glycerol. Fat-rich diets caused an increase in serum free fatty acids and glycerol from 300 and 25 to 450 and 35 $\mu \mathrm{mol} /$ liter, respectively, which returned to the initial levels during prudent diets (not shown). Carbohydrate feeding resulted in a further decrease while energy restriction was associated with a marked rise in circulating concentrations of glycerol (Fig. 1) and free fatty acids (not shown). A new steady state was attained within 3 days during each of the different dietary regimens (Fig. 1). Steady state levels of free fatty acids and of glycerol were significantly lower on carbohydrate-rich diets than during energy restriction $(P \leqq 0.05)$.

Serum lipid concentrations also showed the expected changes (Table II). Total serum cholesterol was highest during fat feeding, declined during prudent diets and even more so on carbohydraterich diets $(P \leqq 0.01)$. Changes in serum triglycerides were inversely related to those seen with cholesterol. Triglyceride concentrations were lowest during fat feeding and slightly increased during prudent diets. They reached peak levels during carbohydrate-rich diets $(P \leqq 0.01)$ and declined to concentrations that were comparable to those seen on fat-rich diets upon energy restriction.

Dietary effects on nonstimulated glycerol-release. "Basal" lipolytic rates of adipocytes obtained under different conditions are shown in Fig. 2. In the absence of adenosine deaminase basal lipolytic activities were low. During the three weight-maintaining diets of different composition, basal activities ranged from 0.3 to $0.7 \mu \mathrm{mol} / 10^{6}$ cells per $180 \mathrm{~min}$. During energy restriction lipolytic rate was doubled on average (NS).

Removal of endogenous adenosine was associated with a significant $(P \leqq 0.01)$ increase in nonstimulated glycerol release (Fig. 2). Adenosine deaminase had a more pronounced effect during high fat feeding and energy restriction than on prudent and carbohydrate-rich diets, respectively (Fig. 2). Lipolytic rates were therefore, lowest during carbohydrate-rich diets. They approximately doubled during fat feeding $(P \leqq 0.05)$ and on average were highest during energy restriction under these conditions ( $P$ $\leqq 0.05$ versus high carbohydrate and prudent diets).

Catecholamines. Illustrated in Fig. 3 are mean dose-response curves of epinephrine in the absence (Fig. $3 A$ ) or presence (Fig. $3 B$ ) of adenosine deaminase. In the absence of adenosine deaminase stimulatory effects could only be observed at micromolar concentrations of the catecholamine (Fig. $3 A$ ). Removal of endogenous adenosine was associated with a marked left shift of the mean dose-response curves. The average dose-response curves were biphasic with $\beta$-adrenergic stimulation occurring in the nanomolar concentration range and $\alpha_{2}$-adrenergic inhibition at concentrations of $0.1 \mu \mathrm{mol} /$ liter and above (Fig. $3 \mathrm{~B}$ ).

The biphasic nature of the dose-response curves of epineph-

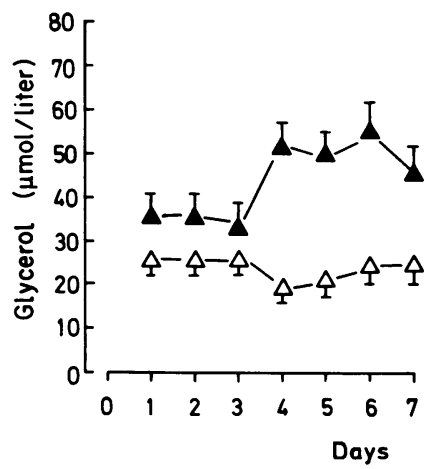

Figure 1. Changes in postabsorptive concentrations of serum glycerol during carbohydrate-rich and energy-restricted diets. Values are pooled data \pm SE from 5 subjects. Blood samples were drawn at 8:00 a.m. after an overnight fast for 12-13 hours. ( $\Delta$ ) highcarbohydrate diet; $(\Lambda)$ energy restriction $(300 \mathrm{kcal} / \mathrm{d})$. 
Table II. Serum Lipid Levels

\begin{tabular}{lcccr}
\hline & Fat-rich diet & Prudent diet & Carbohydrate-rich diet & Energy-restricted diet \\
\hline Cholesterol $(m g / d l)^{*}$ & $185 \pm 15$ & $152 \pm 14$ & $140 \pm 10$ & $160 \pm 12$ \\
Triglycerides $(m g / d l)^{*}$ & $48 \pm 6$ & $54 \pm 6$ & $109 \pm 14$ & $63 \pm 12$ \\
\hline
\end{tabular}

* Values are means $\pm \mathrm{SE}$ of 12 individual determinations carried out in duplicate in each condition.

rine and norepinephrine precluded individual estimates of $E_{\text {so }}$ 's. Therefore, only the effects of isoproterenol and clonidine which are selective for the $\beta$ - and $\alpha_{2}$-adrenergic receptors, respectively were analyzed for diet-induced changes in catecholamine action. Isoproterenol caused a dose-dependent increase in glycerol release irrespective of the preceding diets (Fig. 4). Maximal rates were in the range of 5.0 to $6.0 \mu \mathrm{mol}$ glycerol $/ 10^{6}$ cells per $180 \mathrm{~min}$. Removal of endogenous adenosine resulted in a left-ward shift of the isoproterenol dose-response curve by nearly one order of magnitude under all conditions studied. Isoproterenol sensitivity was not influenced by the preceding diets regardless whether adenosine had been removed or not. In the presence of adenosine deaminase the concentrations of isoproterenol causing half of the maximal effect averaged $0.8 \pm 0.3$ (fatrich diets), $0.8 \pm 0.1$ (prudent diets), $1 \pm 0.3$ (carbohydrate-rich diets), and $0.75 \pm 0.3 \mathrm{pmol} / \mathrm{liter}$ (energy restriction), respectively.

Shown in Fig. 5 are dose-response curves for the $\alpha_{2}$-adrenergic agonist clonidine. The $\alpha_{2}$-adrenergic agonist was capable of almost completely depressing glycerol release under all dietary conditions studied. Sensitivity to clonidine was not substantially changed by the preceding diets. Individual $\mathrm{ED}_{\mathbf{5 0}}$ 's averaged $23 \pm 14,20 \pm 9,13 \pm 6$ and $14 \pm 4 \mathrm{nmol} /$ liter during high-fat, prudent, high-carbohydrate, and energy-restricted diets, respectively. These differences were not statistically significant as also indicated by the fact that the normalized average responses were nearly exactly superimposable (inset to Fig. 5).

$N^{6}$-phenylisopropyladenosine. The nonmetabolisable adenosine analogue $\mathrm{N}^{6}$-phenylisopropyladenosine, which is selective for $A_{1}$-adenosine receptor sites behaved similarly to clonidine
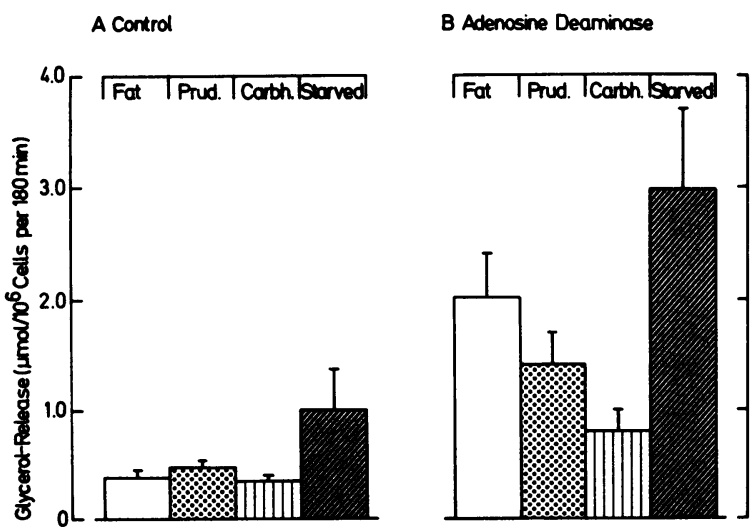

Figure 2. Influence of variations in total energy intake and dietary composition on "basal" lipolytic rates. Data are means \pm SE of 8 experiments carried out in duplicate in the absence $(A)$ or presence $(B)$ of adenosine deaminase $(1.6 \mu \mathrm{g} / \mathrm{ml}$ corresponding to $320 \mathrm{mU} / \mathrm{ml})$. Energy contents and composition of the individual diets are given in Table I. Abbreviations refer to fat-rich (Fat), prudent (Prud), carbohydrate-rich (Carbh), and energy-restricted (starved) diets, respectively. in that it was capable of completely depressing glycerol release (Fig. 6). The dose-response relationships were also not influenced by the preceding diets. Half-maximal inhibition as estimated from individual dose-response curves averaged $2.2 \pm 0.5,1.8 \pm 0.4$, $2.1 \pm 0.4$, and $2 \pm 0.8 \mathrm{nmol} /$ liter during fat-rich, prudent, carbohydrate-rich, and energy-restricted diets. Upon normalization the average responses observed under different dietary conditions fitted with a single dose-response curve (inset to Fig. 6).

Prostaglandin $E_{2}$. Prostaglandin $\mathrm{E}_{2}$ nearly completely depressed lipolysis under all conditions employed (Fig. 7). Maximal effects were observed at prostaglandin $E_{2}$ concentrations ranging from 5 to $50 \mathrm{nmol} /$ liter. However, sensitivity (left-right position of the dose-response curve) of the cells to the antilipolytic action of prostaglandin $\mathrm{E}_{2}$ displayed considerable variation which depended on the preceding diets (Fig. $7 \mathrm{~B}$ ). The median of individual $\mathrm{ED}_{50}$ 's was $2.9 \mathrm{pmol} / \mathrm{liter}$ during the fat-rich diet and 0.4 and $0.6 \mathrm{nmol} /$ liter during the carbohydrate-rich and energy-restricted diets, respectively ( $P \leqq 0.01$ vs. fat feeding). During prudent diets sensitivity was within these extremes (median of individual $\mathrm{ED}_{50}$ 's $27.5 \mathrm{pmol} / \mathrm{liter}$ ) but still significantly lower than during fat-rich diets $(P \leqq 0.01)$.

Insulin. In contrast to all other antilipolytic compounds tested, insulin was incapable of completely inhibiting lipolysis. In addition, the extent of insulin-induced inhibition was critically dependent on the preceding diets. An inhibitory effect of the peptide hormone could be consistently demonstrated only during the high-fat and energy-restricted diets (Fig. 8). During prudent and carbohydrate-rich diets fat cells of only three (prudent diets) or two (carbohydrate-rich diets) of the subjects exhibited a measurable response (not shown).

Insulin sensitivity was also affected by the preceding diets. Except in one subject who exhibited an even larger difference, the peptide hormone was 2-40 times more potent during fat feeding than during energy restriction. On average $\mathrm{ED}_{50}$ was

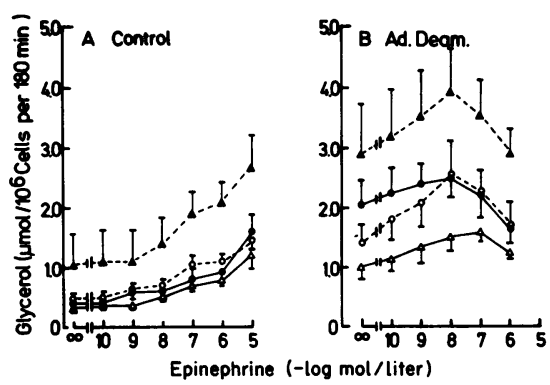

Figure 3. Effects of increasing concentrations of epinephrine under different dietary conditions in the absence $(A)$ or presence $(B)$ of adenosine deaminase $(320 \mathrm{mU} / \mathrm{ml})$. Values are means $\pm \mathrm{SE}$ of eight separate experiments carried out in the same subjects during each dietary period. (๑) Fat-rich diet; (o) prudent diet; $(\Delta)$ carbohydrate-rich diet; ( $\Delta$ ) energy restriction $(300 \mathrm{kcal} / \mathrm{d})$. Ad. Deam., adenosine deaminase. 


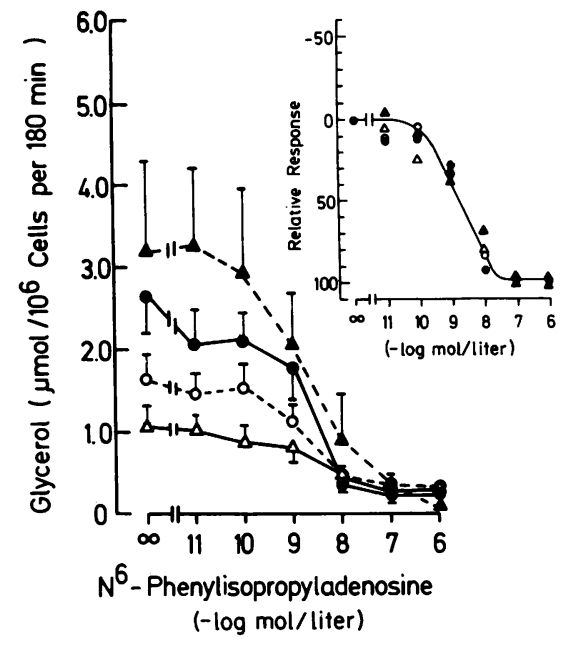

Figure 4. Mean dose-response curves of isoproterenol in adipocytes obtained under different dietary conditions as influenced by adenosine deaminase. Values are means $\pm S E$ of eight separate experiments carried out in the same subjects during each dietary period in absence (๑) or presence $(0)$ of adenosine deaminase $(1.6 \mu \mathrm{g}[320 \mathrm{mU}] / \mathrm{ml})$.

increased from $7 \mathrm{pmol} /$ liter during high-fat diet to $124 \mathrm{pmol} /$ liter during starvation, respectively.

\section{Discussion}

Dietary effects on serum concentrations of lipids, free fatty acids, and glycerol. For practical reasons the same sequence of diets was used in all subjects during the present studies. In order to discern whether this fixed design was likely to produce confounding carryover effects daily determinations of postabsorptive

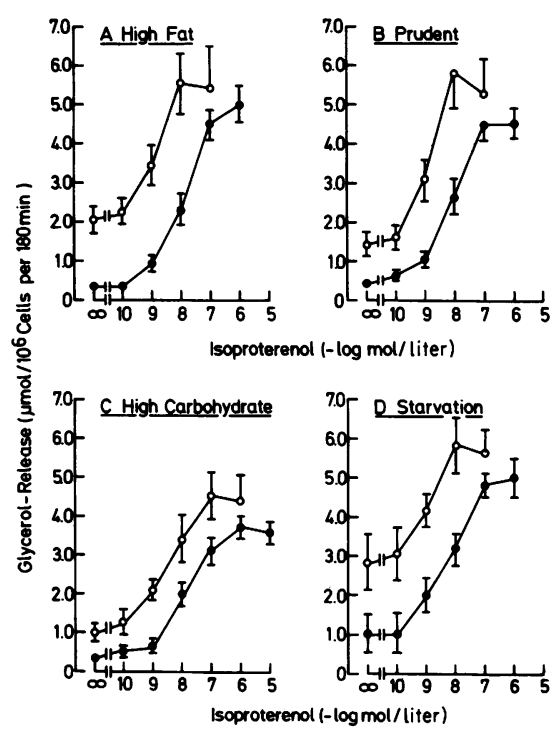

Figure 5. Activity profiles of clonidine in adipocytes obtained under different dietary conditions. Values are means $\pm \mathrm{SE}$ of seven (fat-rich) or eight (other diets) separate experiments carried out in duplicate. The media contained $1.6 \mu \mathrm{g} / \mathrm{ml}$ of adenosine deaminase corresponding to $320 \mathrm{mU} / \mathrm{ml}$. (๑) fat-rich diet; (o) prudent diet; $(\Delta)$ carbohydraterich diet; ( $\Delta$ ) energy restriction $(300 \mathrm{kcal} / \mathrm{d})$. The relative responses shown in the insert are expressed as a percentage of the maximal response.

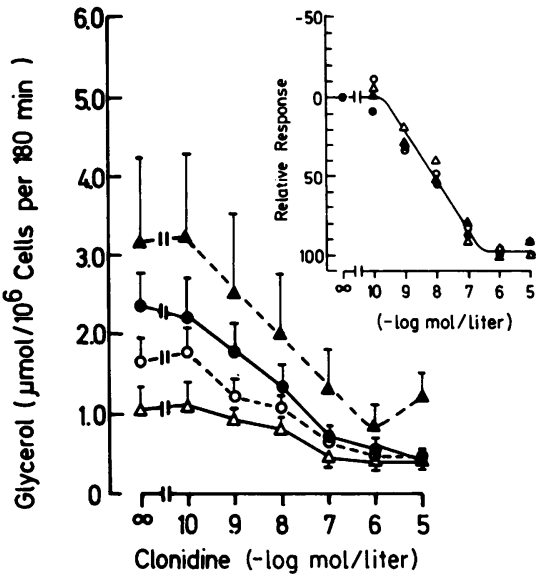

Figure 6. Inhibition by $\mathrm{N}^{6}$-phenylisopropyladenosine of lipolysis in adipocytes from donors receiving diets of varying total energy content and composition. Values are means $\pm \mathrm{SE}$ of eight separate experiments carried out in the same subjects during each dietary period. Conditions and symbols are the same as described in legend to Fig. 5.

concentrations of serum glycerol and free fatty acids were performed in five of the subjects. A new steady state was attained within $3 \mathrm{~d}$ during each of the dietary regimens employed. In addition, the changes in blood lipids observed at the end of each dietary period were essentially the same as noted by others with randomly assigned diets of similar composition (17). It therefore appears improbable that the order of appearance of the different diets per se had a major influence on lipolysis in vitro.

Nonstimulated lipolysis and adenosine action. Previous studies showed that nonstimulated glycerol release of adipocytes from obese subjects is restrained by endogenous adenosine before and during energy restriction (11). Adipocytes from lean subjects are also subject to tonic inhibition by adenosine (Fig. 2). Evidence from animal experiments suggests that changes in adenosine action might contribute to diet-induced variations in lipid mobilization $(18,19)$. However, the effects of $\mathrm{N}^{6}$-phenylisopropyladenosine, which is selective for $A_{1}\left(R_{i}\right)$-adenosine receptors were not changed by the preceding diets in this and former studies

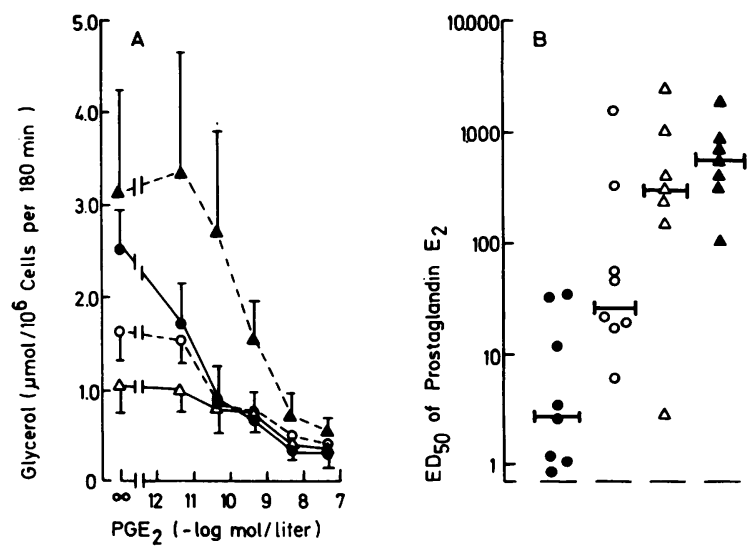

Figure 7. Antilipolytic action $(A)$ and individual $\mathrm{ED}_{50}$ 's $(B)$ of prostaglandin $E_{2}$. Values are means $\pm S E$ of seven (carbohydrate-rich and energy-restricted diets) or eight (fat-rich and prudent diet) separate experiments. The median of individual $\mathrm{ED}_{\mathbf{s}}$ 's for each condition is indicated by horizontal bars. Symbols and conditions are the same as described in the legend to Fig. 5. 


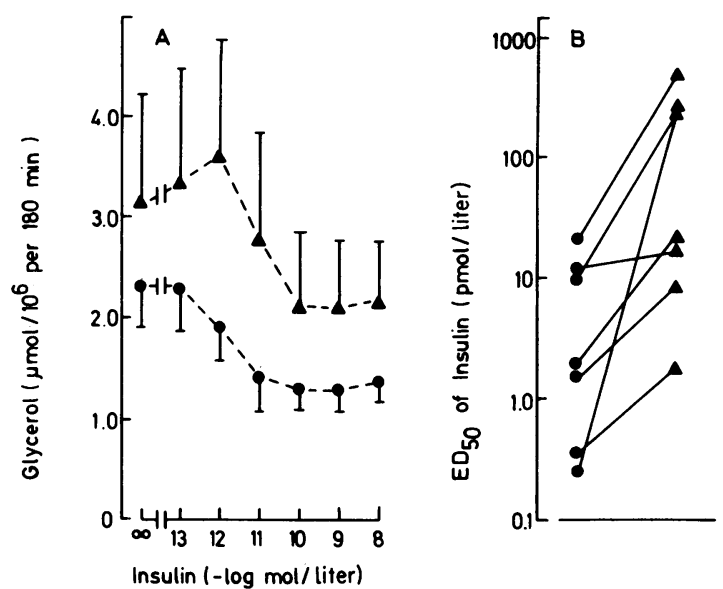

Figure 8. Mean dose-response curves $(A)$ and individual $\mathrm{ED}_{50}$ 's $(B)$ of insulin in adipocytes obtained on fat-rich and energy-restricted diets. Values in $(A)$ are means $\pm \mathrm{SE}$ of seven separate experiments carried out in the same subjects under both conditions the individual $E_{50}$ 's of which are given in $(B)$. For symbols see legend to Fig. 5 .

(12). According to present understanding the diet-induced changes in lipolytic activity are therefore probably unrelated to changes in adenosine action in man.

As in the rat, the lipolytic effects of adenosine deaminase were variable and dependent on the preceding diets (19). At the concentration employed $(320 \mathrm{mU} / \mathrm{ml})$ adenosine deaminase removed all adenosine within seconds (19, Kather et al. Unpublished observations). It therefore, appears justified to conclude that the differences in lipolytic activities seen in the presence of adenosine deaminase reflect diet-induced changes in fat cell metabolism that tend to be obscured by adenosine accumulating during incubations in vitro. The latter conclusion is consistent with previous findings, both in man and rat showing that the confounding effects of endogenous adenosine need careful consideration $(20,21)$.

The mechanism(s) underlying the diet-related variations in lipolytic activity seen in the presence of adenosine deaminase are unknown at present. Adaptive changes in concentrations or activity of various enzymes, e.g., hormone-sensitive triglyceride lipase, phosphoprotein phosphatase(s), protein kinase, cyclic AMP phosphodiesterase, as well as adenylate cyclase catalytic unit could be causally involved. Other possibilities include accumulation of nonadenosine inhibitory agonists of endogenous origin or formation of cytosolic activators of adenylate cyclase activity, the occurrence of which has been described in rat hepatocytes and reticulocytes $(22,23)$.

The physiological meaning of diet-related variability in lipolytic activity observed in the presence of adenosine deaminase is difficult to assess, too. Interestingly, postabsorptive serum concentrations of free fatty acids and glycerol were changed by the preceding diets in a manner very much similar to the dietrelated variations in nonstimulated lipolysis seen in vitro in the presence of adenosine deaminase (Fig. 1). However, circulating concentrations of adenosine are reportedly high enough (100$300 \mathrm{nmol} /$ liter) to completely suppress lipolysis unless adipocytes are protected from circulating adenosine by vascular endothelial cells, which are known to have a high capacity for adenosine removal and degradation (24-26). The answer to the question as to what extent lipolysis is inhibited by adenosine in the intact organism will therefore depend on determination of interstitial adenosine concentrations in adipose tissue in vivo.

Catecholamines. Previous studies showed that energy restriction has only minor, if any influences on the activities of $\alpha_{2}$ - and $\beta$-adrenergic pathways in abdominal adipocytes from obese donors (11). The observation that the effects of the selective $\alpha_{2}$ - and $\beta$-adrenergic agonists clonidine and isoproterenol are not changed by the dietary manipulations employed is consistent with previous conclusions and invites to assume that changes in sensitivity and responsiveness to $\alpha_{2}$ - and $\beta$-adrenergic signals are of minor importance during dietary adaption of fat cell lipolysis in man (11).

Somewhat surprisingly the naturally occurring catecholamines epinephrine and norepinephrine produced a pattern of effects in adipocytes of lean subjects that was opposite to that previously observed in obese volunteers (11). In the presence of adenosine deaminase the dose-response curves of epinephrine and norepinephrine were biphasic with $\beta$-adrenergic stimulation occurring in the physiological (nanomolar; 27, 28) concentration range and $\alpha_{2}$-adrenergic inhibition at $0.1 \mu \mathrm{mol} / \mathrm{liter}$ and above. By contrast, in the obese, $\alpha_{2}$-adrenergic inhibition was predominant and occurred at lower catecholamine concentrations than $\beta$-adrenergic stimulation (11). These latter differences between adipocytes from lean and obese donors could reflect a difference in the balance of the relative activities of $\alpha_{2}$ - and $\beta$-adrenergic pathways. However, adipocytes from obese donors produce more glycerol in the absence of hormones than fat-cells of lean subjects (1-7). As shown in this and previous studies the naturally occurring catecholamines act as pure stimulators when base-line levels are low while the same hormones are inhibitors of fat mobilization when baseline activity is high $(6,11)$. The diverse effects of the naturally occurring catecholamines on fat cells from lean and obese donors, could therefore also be a consequence of the difference in basal lipolytic activities, noted between adipocytes from lean and obese donors.

Insulin. Unlike $\mathrm{N}^{6}$-phenylisopropyladenosine, prostaglandin $E_{2}$, and clonidine the antilipolytic action of insulin does not involve $\mathrm{N}_{\mathrm{i}}$, since it is not blocked by treatment with pertussis toxin (21). The peptide hormone differed from other antilipolytic agents in two important aspects: firstly was insulin incapable of completely inhibiting nonstimulated glycerol release. Secondly insulin's antilipolytic action was profoundly influenced by the preceding diets, while the activity profiles produced by clonidine and $\mathrm{N}^{6}$-phenylisopropyladenosine were not affected at all, indicating that nutritional factors influence insulin's antilipolytic action by mechanisms that are unrelated to the effects of other agents thought to act through inhibition of adenylate cyclase (3).

Partial inhibition of lipolysis in human adipose tissue by insulin has also been observed by others $(29,30)$. However, this feature has never been explicitly mentioned, probably, because no comparisons were made with other antilipolytic agents that are capable of completely suppressing glycerol release. In a previous study with adipocytes from obese donors we were unable to decide whether incomplete inhibition of lipid mobilization is an intrinsic property of insulin's antilipolytic action or might be caused by a postreceptor defect (Kather et al. Unpublished observations). The current observations in adipocytes of ideal weight subjects demonstrate that partial inhibition of lipolysis is a characteristic feature of insulin action in normal man. This is in contrast to the rat where complete inhibition of nonstimulated glycerol release by insulin has been repeatedly demon- 
strated (31). In the present study insulin action was impaired on prudent and carbohydrate-rich diets. By contrast, oral ingestion of glucose has been found to improve the sensitivity of antilipolysis to insulin within $1 \mathrm{~h} \mathrm{(30)}$. However, replacement of approximately one-third of daily energy intake by sucrose for $14 \mathrm{~d}$ also resulted in disappearance of insulin's antilipolytic effect (32). It therefore appears possible that the acute and more chronic effects of ingesting large amounts of carbohydrates, on antilipolysis to insulin may be different or even opposing in man $(30,32)$.

The observation that insulin sensitivity was reduced by energy restriction relative to fat-rich diets is at variance with findings in obese subjects too. Insulin sensitivity has been found to be unaffected or even improved by starvation in overweight subjects $(29,33)$. Comparisons with the current observations are difficult, however, because the prefasting diets were either poorly defined or differed in composition from those employed in the present studies. Kashiwagi et al. (5) reported that antilipolysis to insulin was decreased in adipocytes of moderately obese relative to nonobese subjects. In addition, Arner et al. (34) presented evidence suggesting that obese fat cells may be less flexible than adipocytes of normal weight subjects in adapting to acute nutritional changes. Whether more prolonged dietary manipulations will reveal additional differences between adipocytes from lean and obese donors remains an interesting question for further studies.

Prostaglandin $E_{2}$. Prostaglandins of the E- and F-type are produced and released by adipose tissue (35). The physiological role of eicosanoids in regulation of human fat cell function is not known at present. The observation that sensitivity to prostaglandin $E_{2}$ is influenced by dietary manipulations in a manner similar to insulin could indicate that changes in prostaglandin $\mathrm{E}_{2}$ action are important during dietary adaption. Among the agents thought to have a common coupling pathway through $\mathrm{N}_{\mathrm{i}}$, only prostaglandin $\mathrm{E}_{2}$ displayed diet-related variations in antilipolytic activity. It appears therefore that the diet-induced changes in prostaglandin $E_{2}$ action are confined to the receptor level. Interestingly dietary fatty acids have been shown to influence prostaglandin $\mathrm{E}_{2}$-receptor densities on rat macrophages (36).

In conclusion. The current studies show that variations in total energy intake and dietary composition have characteristic and specific effects on human fat cell lipolysis. The results provide a basic framework necessary for considering how nutritional factors influence lipid mobilization in normal man. Further studies should investigate the mechanisms leading to diet-related variations in nonstimulated glycerol release and insulin action. Also should further work consider whether or not the diet-induced changes in prostaglandin $E_{2}$ action are in fact confined to the receptor level.

\section{Acknowledgments}

The authors are grateful to Miss E. Messmer for skillful technical assistance and are indebted to Mrs. C. Brown for careful preparation of the manuscript. We wish to thank Dr. M. Kohlmeier, Department of Internal Medicine, University of Heidelberg for determination of serum lipids.

This work was supported by grants of the Thyssen-Stiftung Cologne and the Bundesministerium für Forschung und Technologie, Bonn, Federal Republic of Germany.

\section{References}

1. Salans, L. B., and S. W. Cushman. 1978. Relationship of adiposity and diet to the abnormalities of carbohydrate metabolism in obesity. In
Diabetes, Obesity and Vascular Disease, Part 1. Advances in Modern Nutrition. H. M. Katzen and R. J. Mahler, editors. Vol. 2. John Wiley and Sons, New York. 267-301.

2. Czech, M. P., D. K. Richardson, and C. J. Smith. 1977. Biomedical basis of fat cell insulin resistance in obese rodents and man. Metab. Clin. Exp. 29:1957-1978.

3. Hales, C. N., J. P. Luzio, and K. Siddle. 1978. Hormonal control of adipose-tissue lipolysis. Biochem. Soc. Symp. 43:97-135.

4. Giudicelli, Y., D. Lacasa, and B. Agli. 1982. Alterations induced by prolonged fasting: opposite effects on the $\beta$-adrenergic receptor-coupled adenylate cyclase system and on lipolysis in fat cells from rat. Eur. $J$. Biochem. 121:301-308.

5. Kashiwagi, A., C. Bogardus, S. Lillioja, T. P. Hueckstaedt, D. Brady, M. Verso, and J. E. Foley. 1984. In vitro insensitivity of glucose transport and antilipolysis to insulin due to receptor and postreceptor abnormalities in obese Pima indians with normal glucose tolerance. $\mathrm{Me}$ tab. Clin. Exp. 33:772-777.

6. Berlan, M., and M. Lafontan. 1985. Evidence that epinephrine acts preferentially as an antilipolytic agent in abdominal human subcutaneous fat cells: assessment by analysis of beta- and alpha ${ }_{2}$-adrenoceptors properties. Eur. J. Clin. Invest. 15:341-348.

7. Kahn, C. R. 1978. Insulin resistance, insulin insensitivity and insulin responsiveness. A necessary distinction. Metab. Clin. Exp. 27: 1893-1902.

8. Kather, H. 1981. Hormonal regulation of adipose tissue lipolysis in man. Implications for the pathogenesis of obesity. Triangle. 20:131143.

9. Denton, R. M., R. W. Brownsey, and G. J. Belsham. 1981. A partial view on the mechanism of insulin action. Diabetologia. 21:347362.

10. Gilman, A. G. 1984. G proteins and dual control of adenylate cyclase. Cell. 36:577-579.

11. Kather, H., E. Wieland, B. Fischer, A. Wirth, and G. Schlierf. 1985. Adrenergic regulation of lipolysis in abdominal adipocytes of obese subjects during caloric restriction: reversal of catecholamine action caused by relief of endogenous inhibition. Eur. J. Clin. Invest. 15:30-37.

12. Kather, H., E. Wieland, B. Fischer, and G. Schlierf. 1985. Antilipolytic effects of $\mathrm{N}^{6}$-phenylisopropyladenosine and prostaglandin $\mathrm{E}_{2}$ in fat cells of obese volunteers before and during energy restriction. Biochem. J. 231:531-535.

13. Rodbell, M. 1964. Metabolism of isolated fat cells. J. Biol. Chem. 239:375-384.

14. Kather, H., and E. Wieland. 1984. Glycerol. Luminometric Method. Methods Enzymatic Anal. 6:510-518.

15. Kather, H., and E. Wieland. 1985. Free Fatty Acids: Luminometric Method. Methods Enzymatic Anal. 8:25-34.

16. Kohlmeier, M., G. Stricker, and G. Schlierf. 1985. Influences of "normal" and "prudent" diets on biliary and serum lipids in healthy women. Am. J. Nutr. 42:1201-1205.

17. Grundy, S. M. 1986. Comparison of monounsaturated fatty acids and carbohydrates for lowering plasma cholesterol. N. Engl. J. Med. 314 745-748.

18. Chohan, P., C. Carpenter, and E. D. Saggerson. 1984. Changes in the anti-lipolytic action and binding to plasma membranes of $\mathrm{N}^{6}-\mathrm{L}$ phenylisopropyladenosine in adipocytes from starved and hypothyroid rats. Biochem. J. 223:53-59.

19. Honnor, R. C., G. S. Dhillon, and C. Londos. 1985. cAMPdependent protein kinase and lipolysis in rat adipocytes. I. Cell preparation, manipulation and predictability in behavior. J. Biol. Chem. 260: 15122-15129.

20. Honnor, R. C., S. Gurpreet, and C. Londos. 1985. cAMP dependent protein kinase and lipolysis in rat adipocytes. II. Definition of steady state relationship with lipolytic and antilipolytic modulators. $J$. Biol. Chem. 260:15130-15138.

21. Kather, H., W. Bieger, G. Michel, K. Aktories, and K. H. Jakobs. 1985. Human fat cell lipolysis is primarily regulated by inhibitory modulators acting through distinct mechanisms. J. Clin. Invest. 76:15591565 . 
22. Shane, E., M. Yeh, A. S. Feigin, J. M. Owens, and J. P. Billzikian 1985. Cytosol activator protein from rat reticulocytes requires the stimulatory guanine nucleotide-binding protein for its action on adenylate cyclase. Endocrinology. 117:255-263.

23. Sahyoun, N., H. LeVine III, P. Stenbuck, and P. Cuatrecasas. 1983. Cytosolic activator of adenylate cyclase: reconstitution, characterization, and mechanism of action. Proc. Natl. Acad. Sci. USA. 80: 3646.

24. Ontyd, J., and J. Schrader. 1984. Measurement of adenosine inosine and hypoxanthine in human plasma. J. Chromatography. 307: 404-409.

25. German, D. C., and N. M. Kredich. 1984. A radioenzymatic assay for plasma adenosine. Anal. Biochem. 142:532-541.

26. Gorman, M. W., J. B. Bassingthwaighte, R. A. Olsson, and H. V. Sparks. 1986. Endothelial cell uptake of adenosine in canine skeletal muscle. Am. J. Physiol. 250:H482-H489.

27. Galster, A. D., W. E. Clutter, P. E. Cryer, J. A. Collins, and D. M. Bier. 1981. Epinephrine plasma thresholds for lipolytic effects in man. Measurements of fatty acid transport with $1-\left[{ }^{13} \mathrm{C}\right]$ palmitic acid. $J$. Clin. Invest. 67:1729-1738.

28. Sjöström, L., Y. Schutz, F. Gudrichet, L. Hegnell, P. G. Pittet, and E. Jéguier. 1983. Epinephrine sensitivity with respect to metabolic rate and other variables in women. Am. J. Physiol. 245:E431-E442.

29. Arner, P., J. Bolinder, P. Engfeldt, and J. Östman. 1981. The antilipolytic effect of insulin in human adipose tissue in obesity, diabetes mellitus, hyperinsulinemia and starvation. Metab. Clin. Exp. 30:753760.

30. Arner, P., J. Bolinder, and J. Östman. 1983. Marked increase in insulin sensitivity of human fat cells 1 hour after glucose ingestion. $J$. Clin. Invest. 71:709-714.

31. Londos, C., R. C. Honnor, and G. S. Dhillon. 1985. cAMPdependent protein kinase and lipolysis in rat adipocytes. III. Multiple modes of insulin regulation of lipolysis and regulation of insulin responses by adenylate cyclase regulators. J. Biol. Chem. 260:15139-15145.

32. Smith, U., E. Cablin, and T. Scherstén. Sucrose feeding in man. Effects on lipolysis and antilipolytic action after glucose ingestion. Acta Med. Scand. 194:147-150.

33. Pederson, O., E. Hjøllund, and N. Schwarz-Sørensen. 1982. Insulin receptor binding and insulin action in human fat cells: effects of obesity and fasting. Metab. Clin. Exp. 31:884-895.

34. Arner, P., J. Bolinder, P. Engfeldt, J. Hellmér, and J. Östman. 1984. Influence of obesity on the antilipolytic effect of insulin in isolated human fat cells obtained before and after glucose ingestion. J. Clin. Invest. 73:673-680.

35. Chang, J., G. P. Lewis, and P. Piper. 1977. Inhibition by glucocorticoids of prostaglandin release from adipose tissue in vitro. $B r . J$. Pharmacol. 59:425-432.

36. Opmer, F. A., M. J. P. Adolfs, and J. L. Bonta. 1984. Regulation of prostaglandin $\mathrm{E}_{2}$ receptors in vivo by dietary fatty acids in peritoneal macrophages from rats. J. Lipid Res. 25:262-268. 